Article

\title{
Anti-Inflammatory Properties of Bellevalia saviczii Root Extract and Its Isolated Homoisoflavonoid (Dracol) Are Mediated by Modification on Calcium Signaling
}

\author{
Monica Savio ${ }^{1,+}$, Mohammed Farhad Ibrahim ${ }^{2,3,+}$, Chiara Scarlata ${ }^{1}$, Matteo Orgiu ${ }^{4}$, \\ Giuseppe Accardo ${ }^{1}$, Abdullah Shakur Sardar ${ }^{5}$, Francesco Moccia ${ }^{4} \mathbb{D}$, Lucia Anna Stivala ${ }^{1, *}$ \\ and Gloria Brusotti ${ }^{2}$ (D) \\ 1 Department of Molecular Medicine, Immunology and General Pathology Unit, via Ferrata 9, \\ University of Pavia, 27100 Pavia, Italy; monica.savio@unipv.it (M.S.); \\ chiara.scarlata01@universitadipavia.it (C.S.); giuseppe.accardo01@universitadipavia.it (G.A.) \\ Department of Drug Sciences, viale Taramelli 12, University of Pavia, 27100 Pavia, Italy; \\ gardy1988@gmail.com (M.F.I.); gloria.brusotti@unipv.it (G.B.) \\ 3 Department of Environmental Science, College of Science, University of Salahaddin-Erbil, Erbil 44001, Iraq \\ 4 Department of Biology and Biotechnology “L. Spallanzani” via Forlanini 6, University of Pavia, \\ 27100 Pavia, Italy; matteo.orgiu01@universitadipavia.it (M.O.); francesco.moccia@unipv.it (F.M.) \\ 5 Department of Biology, College of Education, University of Salahaddin-Erbil, Erbil 44001, Iraq; \\ abdullah.sardar@su.edu.krd \\ * Correspondence: luciaanna.stivala@unipv.it; Tel.: +39-0382-986337; Fax: +39-0382-986893 \\ + These authors contributed equally to this manuscript.
}

Received: 25 July 2019; Accepted: 14 September 2019; Published: 17 September 2019

\begin{abstract}
Bellevalia saviczii is a medicinal plant used as anti-rheumatic and anti-inflammatory herbal remedy in Iraqi-Kurdistan. The aim of this study was to evaluate the anti-inflammatory activity of its extract and the isolated homoisoflavonoid (Dracol) by studying the $\mathrm{Ca}^{2+}$-dependent NF-kB pathway. Nuclear translocation of p65 NF-kB subunit, as parameter of NF-kB activation, was visualized in human leukemic monocytes by immunofluorescence and Western blot analyses, after cell treatment with B. saviczii root extract or Dracol followed by Lipopolysaccharide stimulation. In parallel, $\mathrm{Ca}^{2+}$ signals responsible for NF-kB activation and levels of inflammatory cytokines were investigated. LPS-induced p65 translocation was evident in monocytes and both treatments, in particular that with Dracol, were able to counteract this activation. Intracellular $\mathrm{Ca}^{2+}$ oscillations were halted and the cytokine release reduced. These results confirm the traditional anti-inflammatory efficacy of $B$. saviczii and identify one of the molecules in the extract which appears to be responsible of this action.
\end{abstract}

Keywords: Bellevalia saviczii; homoisoflavoinoids; NF-kB; $\mathrm{Ca}^{2+}$ signaling

\section{Introduction}

Bellevalia saviczii, a perennial plant belonging to the family of Asparagaceae, represents a plant genus particularly rich in homoisoflavonoids, a special subclass of flavonoids, rarely found in nature but responsible for the biological activity of Bellevalia species used in traditional medicine by people from Mediterranean to Central Asia [1,2]. In particular, B. saviczii is one of the most common local plants of Kurdistan. Traditionally, as handed down orally, it is application as wraps and infusions anti-rheumatic and anti-inflammatory remedy, however their use has not been documented yet in any reports. Homoisoflavonoids, abundant in genus Bellevalia, have received much attention over the past 30 years in the research and development of natural bioactive 
compounds. Until now, about 240 homoisoflavonoids have been isolated and identified, which could be classified into five structural categories, sappanin, scillascillin, brazilin, caesalpin and protosappanin-types. They have been reported with a broad range of bioactivities, including anti-microbial, anti-mutagenic, immunomodulatory, anti-diabetic, cytotoxic [3,4], antioxidant [5-7], anti-angiogenic, vasorelaxant and anti-inflammatory effects [8-10]. In the sappanin-type, 2,3dihydro-3,5-dihydroxy-7-methoxy-3-[(4-methoxyphenyl)-methyl]-8methyl-4H-[1]benzopyr-an-4-one, for which the trivial name Dracol has been proposed, is a natural compound isolated for the first time by Hernandez et al. in 2006 from genus Dracaena draco together with another compound namely icodeside [3]. Whereas this last compound showed moderate cytotoxicity against human HL-60 and A-431 cells, as determined by the MTT assay after treatment with different concentrations for $72 \mathrm{~h}$, Dracol was completely ineffective $\left(\mathrm{IC}_{50}>100 \mu \mathrm{M}\right)$.

Considering that the most common use in traditional medicine of B. saviczii extract is as anti-inflammatory remedy, in this work its potential anti-inflammatory properties were investigated by studying the nuclear factor-kB (NF-kB) activation in human leukemic monocytic cell line (THP1). This protein is included in a family of transcription factors implicated in inflammation, immune response, cell survival and cancer [1,2]. At the basal level, NF-kB is localized in the cytoplasm and its activity is normally suppressed by the interaction with IkB inhibitory proteins, which thereby mask NF-kB nuclear localization signals [11-13]. However, in response to specific external stimuli, including pro-inflammatory cytokines like TNF $\alpha$, IL1 $\beta$ or endotoxins (Lipopolysaccharide, LPS), viral infection, oxidants, phorbol esters and ultraviolet irradiation, the IkB component of the complex is phosphorylated by IKK $\beta$, subsequent degraded and ubiquitinated, resulting in translocation of NF-kB into the nucleus and the induction of target gene transcription [14]. This nuclear translocation of the p50-p65 subunits of NF-kB triggers pro-inflammatory cytokine gene expression such as inducible nitric oxide synthase (iNOS), cyclooxygenase 2 (COX2), TNF $\alpha$, IL1 $\beta$ and IL6. The nuclear translocation of NF-kB may also be triggered by oscillations in intracellular $\mathrm{Ca}^{2+}$ concentration $\left(\left[\mathrm{Ca}^{2+}\right]_{\mathrm{i}}\right)$, which recruit the $\mathrm{Ca}^{2+}$-dependent decoders calcineurin and calmodulin to promote IkB degradation [15-18]. Notably, LPS was found to recruit NF-kB through an oscillatory $\mathrm{Ca}^{2+}$ signal in several cell types, such as primary rat lung microvascular endothelial cells [19] and mouse microglial cells [20]. Intracellular $\mathrm{Ca}^{2+}$ oscillations provide the most suitable waveform to selectively engage NF-kB rather than other $\mathrm{Ca}^{2+}$-dependent transcription factors, such as the nuclear factor of activated $\mathrm{T}$ cells (NFAT), and permit persistent nuclear NF-kB expression [21]. The role of $\mathrm{Ca}^{2+}$ signaling in LPS-induced NF-kB activation in THP1 cells, as well as in human primary monocytes, remains, however, unclear.

Aberrant NF-kB activity is associated with various inflammatory diseases including arthritis, cancer, and atherosclerosis $[6,7,10-12]$. Thus, in the need of a more effective therapy for the treatment of inflammatory diseases, specific inhibition of p65 translocation, related to reduced NF-kB activity represents a rational target [14].

Therefore, this study aims at investigating the anti-inflammatory properties of the $B$. saviczii root methanol extract (BRME) and its isolated compound (Dracol) against LPS-induced inflammatory stimulus in THP1 cells. Here, we report that both extract and its component Dracol protected against inflammatory response induced by LPS. These findings, for the first time, demonstrate that using B. saviczii plant extract, containing bioactive compounds (homoisoflavonoids), might be beneficial to counteract inflammatory diseases.

\section{Results}

The aim of this investigation was to establish whether BRME and its isolated compound, Dracol, are able to contrast LPS-induced inflammatory response of leukemic monocytes, thereby confirming the documented anti-inflammatory properties of this plant in traditional medicine. The extraction of B. saviczii root, the purification of the homoisoflavonoids Dracol and its characterization by HPLC-DAD MS method has been described in Figure 1 and Supplementary Material S1. 


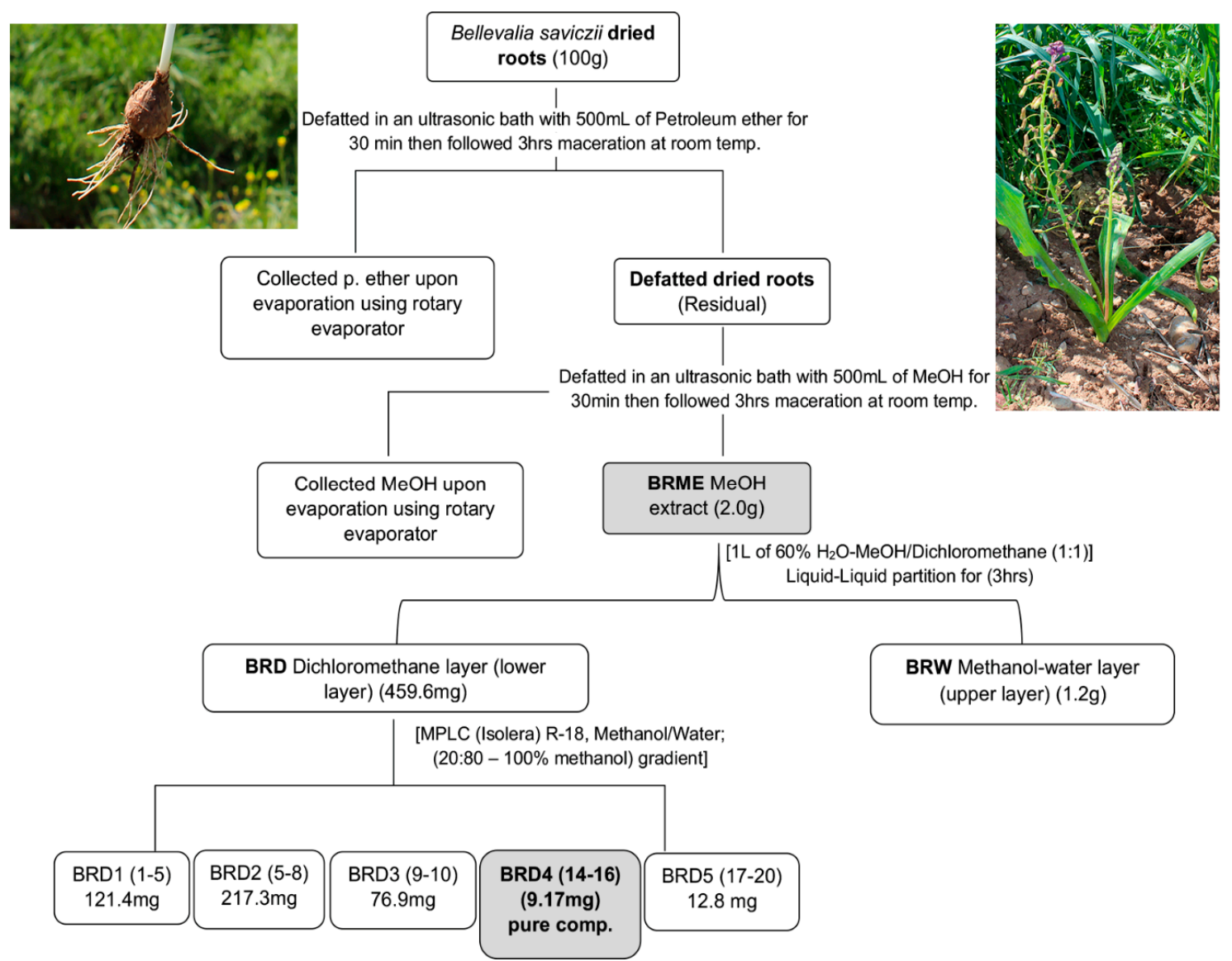

Figure 1. Scheme for extraction and purification of B. saviczii preparation.

The proposed experimental model, consisting of the nuclear translocation of p65 NF-kB subunit, has been already used [13] and represents a simple and useful tool to study anti-inflammatory activity of bioactive compounds. The evaluation of p65 NF-kB subunit, both by immunofluorescence and Western blot analysis, was coupled to functional evaluation of THP1 cell viability and proliferation. In addition, the levels of inflammatory cytokines and calcium signaling were investigated trying to clarify the mechanism of action of B. saviczii root extract and its isolated compound Dracol.

\subsection{Cell Viability and Proliferation Assays}

Preliminary experiments, performed to study the cytotoxic effect of BRME and Dracol by the MTT test (Figure 2A), showed that both do not significantly affect THP1 cell survival or growth at all the concentrations used, after $24 \mathrm{~h}$ of treatment. These results were in agreement with those of Hernández et al. [3] that demonstrated a completely inefficacy of Dracol in exerting toxicity on HL-60 and A-431 cells. Due to this non-toxic effect (about 10\%), we chose the concentrations of 10 and $100 \mu \mathrm{M}$ for Dracol and 62.5 up to $500 \mu \mathrm{g} / \mathrm{mL}$ for BRME for all the subsequent experiments.

The MTT is a test for assessing not only cell toxicity and death but also cell proliferation. However, to better distinguish cytotoxic from cytostatic effect of the compounds, DNA synthesis was evaluated by BrdU incorporation and flow cytometry analysis. The treatment of $24 \mathrm{~h}$ with BRME and Dracol did not result in any significant change in THP1 cell proliferation (Figure 2B,C).

These data are in contrast with Valente et al. that demonstrated antiproliferative activity of D. draco leaf and fruit extracts $(0-400 \mu \mathrm{g} / \mathrm{mL})$ in human colon and renal tumour cells in vitro, whereas a weak effect was observed in HepG2 cells. The highest activity was observed with the leaf extract [22]. Trypan blue staining confirmed this weak cytotoxic effect that was related to low level of cell death, 
even at the higher concentrations of $200 \mu \mathrm{M}$ Dracol and $1000 \mu \mathrm{g} / \mathrm{mL}$ BRME, and a longer incubation time (48, 72 and 96 h) (Supplementary Material S2).
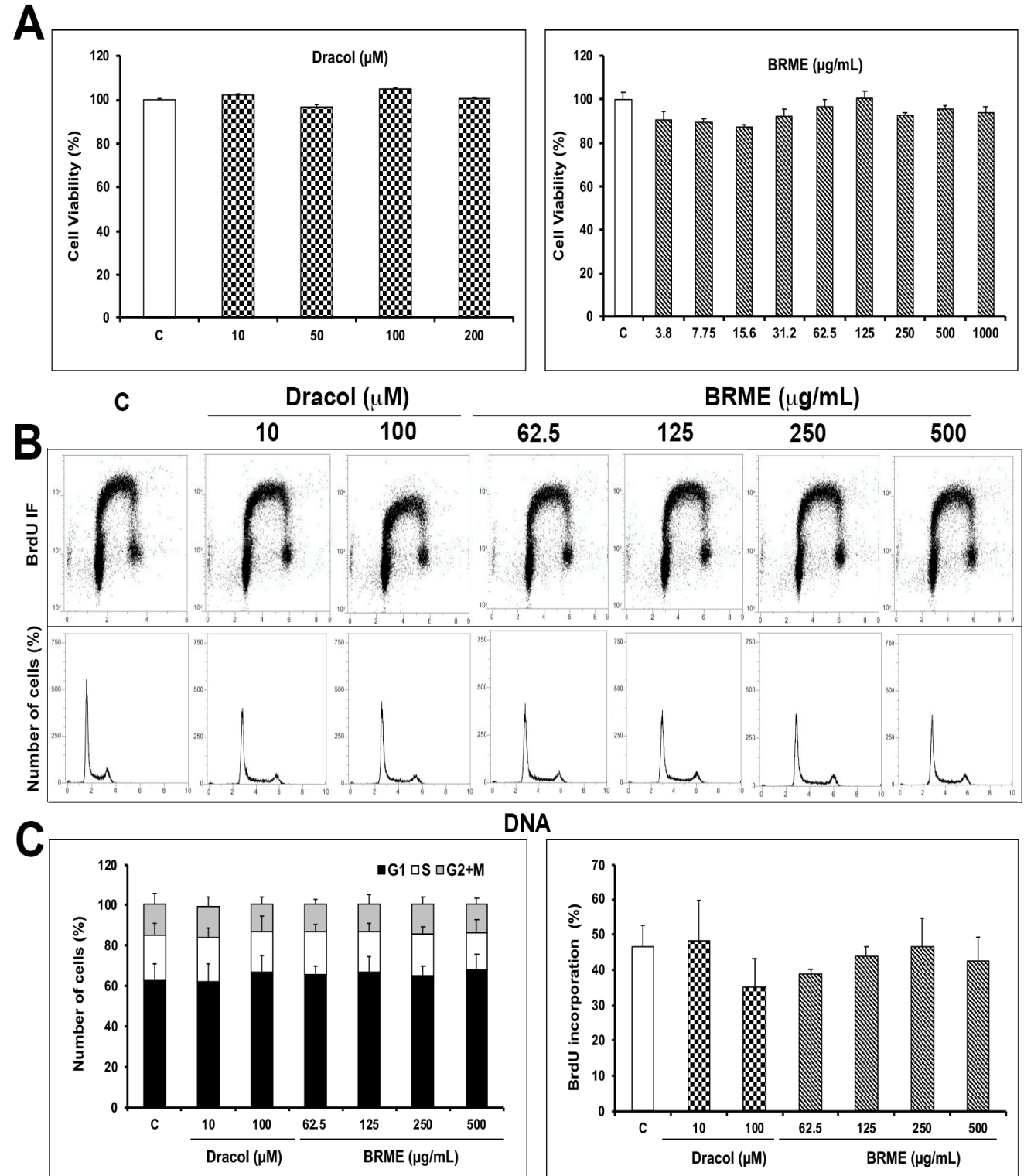

DNA

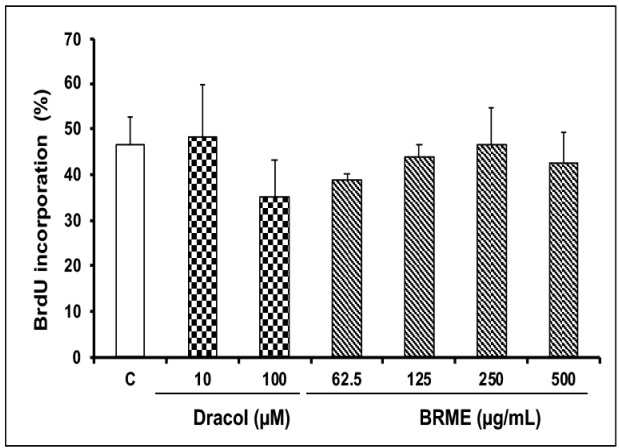

Figure 2. Assessment of THP1 cell viability and proliferation after Dracol and BRME treatment. (A) Effect of $24 \mathrm{~h}$ treatment with increasing concentrations of Dracol and BRME on THP1 viability as evaluated by MTT assay. Values are expressed as percentage of untreated cells (control). All results are expressed as mean \pm SD from three independent experiments. (B) Cell cycle phase distribution was evaluated by flow cytometry after BrdU incorporation analysis and staining with PI. Ten thousand cells were analysed from each sample, and statistical analysis of the mean fluorescence intensity was performed with Attune ${ }^{\mathrm{TM}}$ NxT Software. (C) DNA synthesis was analysed by a biparametric flow cytometry analysis of BrdU incorporation versus DNA content. Representative profiles of cell cycle distribution and the relative quantification of the percentage of BrdU incorporation were calculated in the middle of the $S$ phase.

\subsection{Optimization of Inflammatory Model: Preliminary Evaluation}

Previous experiments on THP1 cells treated with different concentrations allowed to find the best LPS concentration to induce NF-kB activation. In particular, THP1 cells were treated in serum free medium with $0.01-0.1-1 \mu \mathrm{g} / \mathrm{mL}$ LPS for $4 \mathrm{~h}$. As shown in Figure $3 \mathrm{~A}, \mathrm{~B}$, a dose-dependent increase of 
NF-kB positive nuclei was observed; in these conditions, the viability remains rather high, showing a $20 \%$ of reduction only at the highest LPS concentration. No differences were evident at both incubation time used, 2 and $4 \mathrm{~h}$ (Figure 3C).

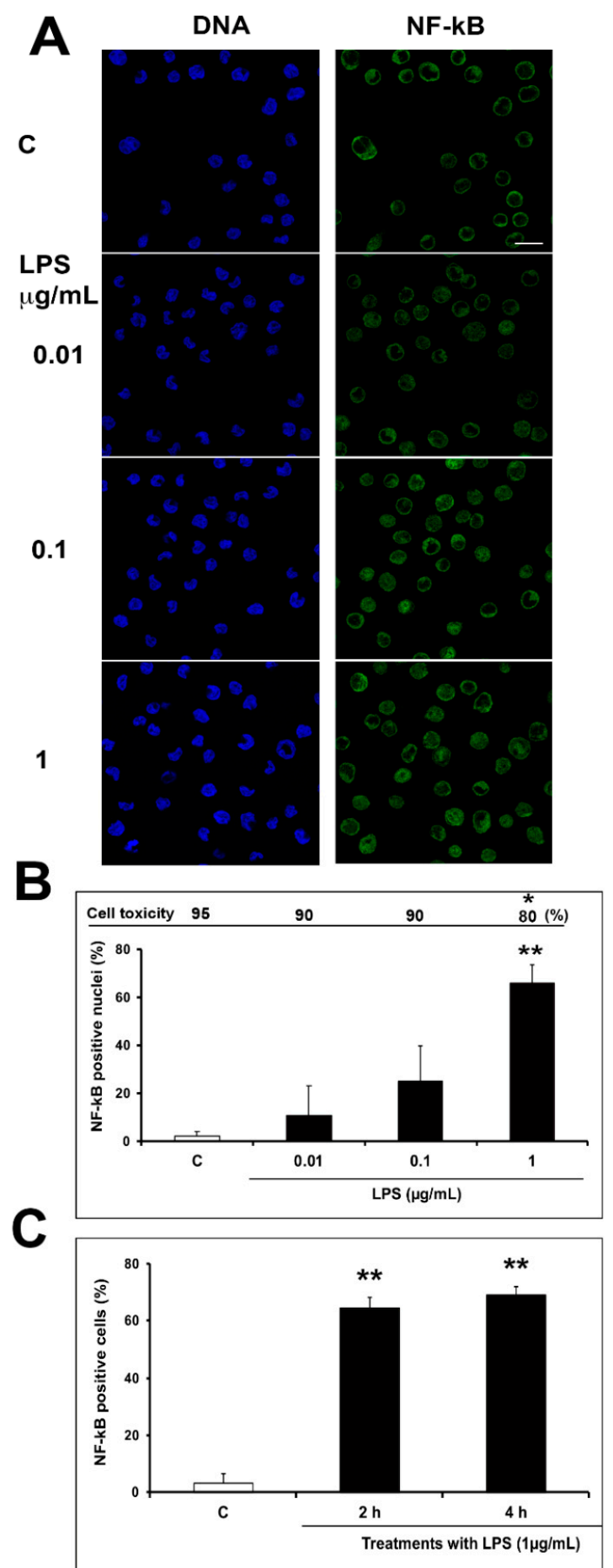

Figure 3. Optimization of LPS concentrations for NF-kB activation in THP1 cells. (A) NF-kB representative images obtained after immunostaining of THP1 cells treated with different concentrations of LPS and (B) the relative quantification of NF-kB-stained positive cells. Nuclear translocation of NF-kB was determined by immunofluorescence microscopy using antibody directed against p65 subunit. Cell toxicity was evaluated by Trypan blue assay, after treatment with LPS at the different concentrations. (C) NF-kB activation after 2 and $4 \mathrm{~h}$ of treatment with $1 \mu \mathrm{g} / \mathrm{mL}$ LPS. Scale bar $=20 \mu \mathrm{m}$. All results are expressed as mean \pm SD from three independent experiments. ${ }^{* *} p \leq 0.01$ by Student's $t$-test. 
Only a weak cytotoxic effect related to a low number of dead cells (about 20\%) was detectable at the highest concentration of LPS (Figure 3B). Therefore, $4 \mathrm{~h} 1 \mu \mathrm{g} / \mathrm{mL}$ LPS treatment was considered in the subsequent experiments. The p65 translocation using immunofluorescence analysis has been used by Hund et al. [13], but with different cell type and inflammatory stimulus; in particular, they used endothelial cells and TNF $\alpha$, respectively.

\subsection{Effect of BRME and Dracol on LPS-Activated THP1}

Before determining the effects of BRME and Dracol on LPS-induced cytotoxicity and NF-kB activation, THP1 cells were treated with each compound alone for $24 \mathrm{~h}$ to check for a possible effect on NF-kB. The results showed that they do not exert any modulation on NF-kB activity (Supplementary Material S2). One $\mu \mathrm{g} / \mathrm{mL}$ LPS for $4 \mathrm{~h}$ confirmed a weak not significant reduction of viability (about $10 \%$ ) as shown in Figure $4 \mathrm{~A}$.
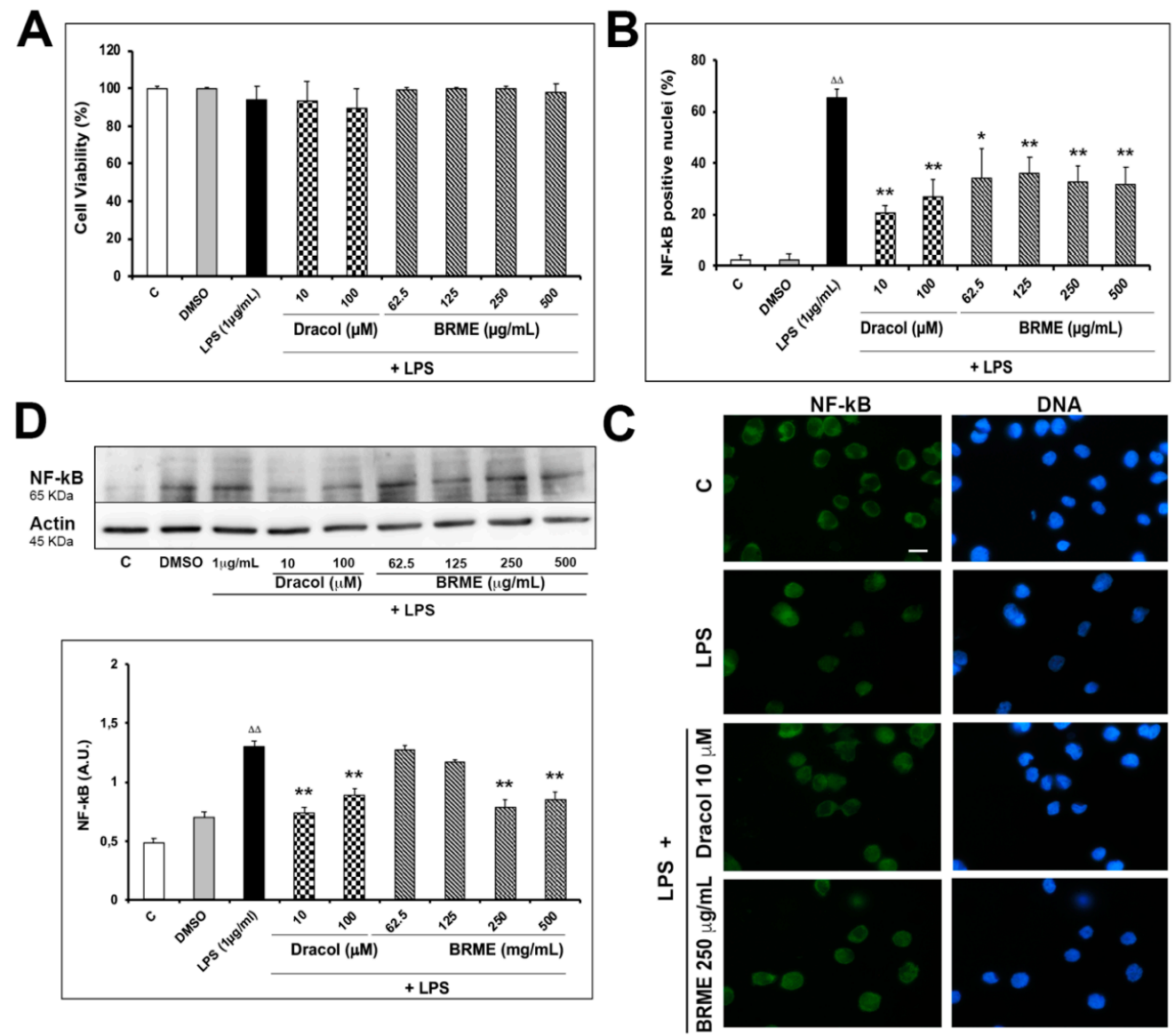

Figure 4. LPS-induced NF-kB cellular level is prevented by treatment with BRME and Dracol. (A) Effect of $24 \mathrm{~h}$ treatment with Dracol and BRME in the presence of $1 \mu \mathrm{g} / \mathrm{mL}$ LPS on THP1 viability evaluated by MTT assay. Values are expressed as percentage of untreated cells (control). DMSO, dimethyl sulfoxide. (B) Quantification of NF-kB positive nuclei after treatment with Dracol and BRME in the presence of LPS, and (C) their representative images. (D) The correspondent Western blotting in control and treated samples as indicated and quantitative analysis of the bands. Scale bar $=10 \mu \mathrm{m}$. Values compared to positive control (LPS) and control cells are expressed as mean \pm SD from at least three independent experiments. ${ }^{*} p \leq 0.05,{ }^{* *} p \leq 0.01$ by Student's $t$-test vs. LPS sample. $\Delta \Delta p \leq 0.01$ vs. C (control cells).

While BRME was able to counteract this cytotoxicity, Dracol (10-100 $\mu \mathrm{M})$ seems to have no effect as compared with only LPS treated cells. Both Dracol and BRME at all concentrations used, were able to reduce in a highly significant manner the LPS-induced NF-kB activation (Figure 4B,C), as demonstrated both by immunofluorescence staining and Western blotting experiments (Figure 4D). These data, for the 
first time, support the traditional anti-inflammatory properties of B. saviczii, showing that both total root extract and the isolated compound Dracol prevent THP1 inflammatory response. Inflammation has been considered as a concourse of several diseases, such as type 2-diabetes, cardiovascular, neurodegenerative and neoplastic diseases [23-25]; therefore, it is important to highlight potent inflammatory modulators present in herbal remedies.

\subsection{Cytokine Analysis}

To better characterize the anti-inflammatory properties of Dracol and BRME, the levels of TNF $\alpha$, IL6 and IL1 $\beta$ were also evaluated. In agreement with the data obtained for NF-kB activation, the level of TNF $\alpha$ was significantly increased after treatment with LPS, as shown in Figure 5A; both Dracol and BRME, at all concentrations tested, significantly inhibited the release of the pro-inflammatory cytokine. While, similar results were obtained for IL6 and IL1 $\beta$ (Figure 5B,C), in which only the highest concentrations of both Dracol and BRME are able to significantly inhibit cytokine release.
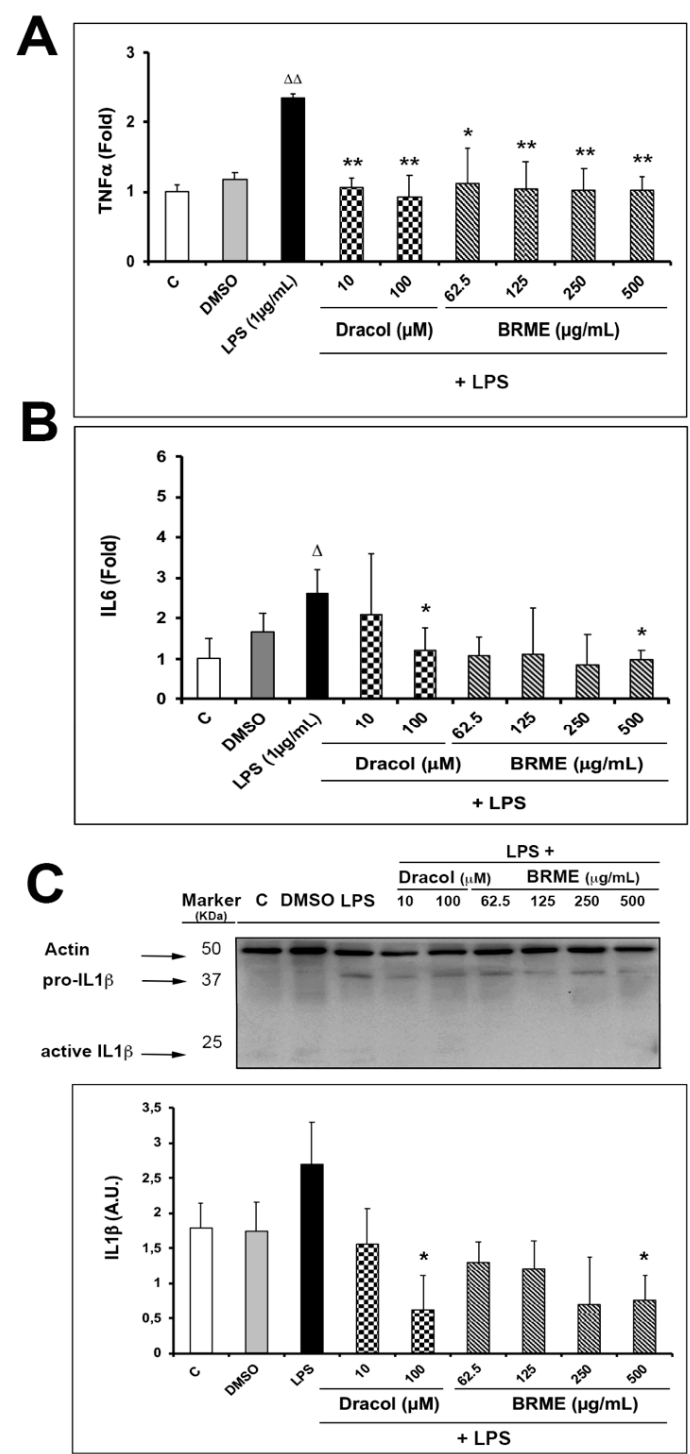

Figure 5. Pro-inflammatory cytokine levels after treatment with BRME and Dracol in the presence of $1 \mu \mathrm{g} / \mathrm{mL}$ LPS. TNF $\alpha$ and IL6 (A,B) levels are expressed as percentage in comparison with control. (C) Western Blotting and data analysis of the protein level of IL1 $\beta$. Values compared to positive control (LPS $1 \mu \mathrm{g} / \mathrm{mL}$ ) and control cells are expressed as mean \pm SD from five independent experiments. ${ }^{*} p \leq 0.05,{ }^{* *} p \leq 0.01$ by Student's $t$-test vs. LPS sample. $\Delta \Delta p \leq 0.01$ vs. C (control cells). 


\subsection{Calcium Signalling}

It has long been known that intracellular $\mathrm{Ca}^{2+}$ oscillations drive the nuclear translocation of NF-kB by favouring the $\mathrm{Ca}^{2+}$-dependent phosphorylation of IKB [15-18]. LPS, in turn, is able to induce repetitive intracellular $\mathrm{Ca}^{2+}$ oscillations by inducing a concerted interplay between inositol-1,4,-5-trisphosphate ( $\mathrm{InsP}_{3}$ )-dependent $\mathrm{Ca}^{2+}$ release and store-operated $\mathrm{Ca}^{2+}$ entry (SOCE), thereby inducing NF-kB activation [19,20,25]. We found that the acute addition of $1 \mu \mathrm{g} / \mathrm{mL}$ LPS caused an increase in $\left[\mathrm{Ca}^{2+}\right]_{\mathrm{i}}$ in the $54.1 \pm 13.8 \%(n=377)$ of THP1 cells loaded with the $\mathrm{Ca}^{2+}$-sensitive fluorochrome, Fura-2/AM. This $\mathrm{Ca}^{2+}$ signal consisted either in a single $\mathrm{Ca}^{2+}$ spike $(59.5 \pm 17.7 \%)$ (Figure 6A) or in repetitive $\mathrm{Ca}^{2+}$ oscillations that persisted throughout the period of recording $(40.5 \pm 17.7 \%)$ (Figure 6B).

A

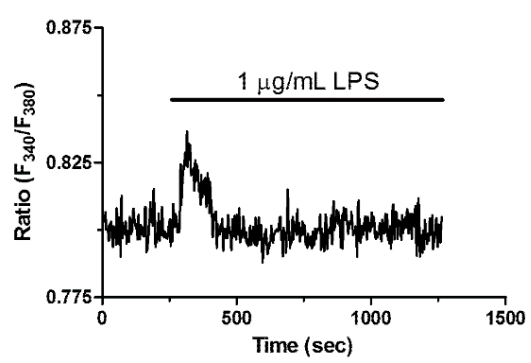

C

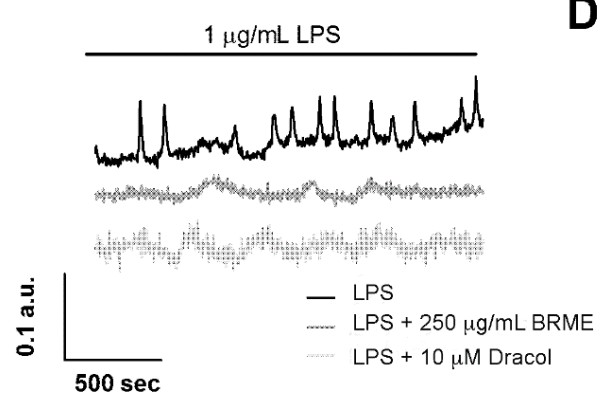

$\mathbf{E}$

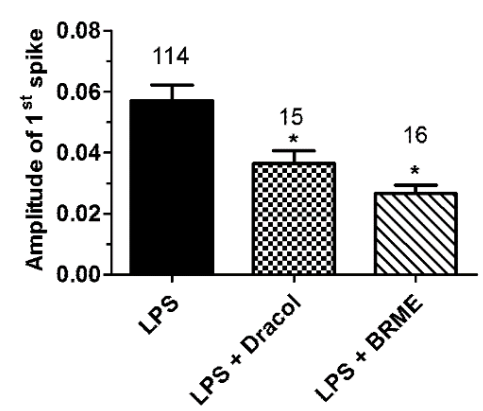

D

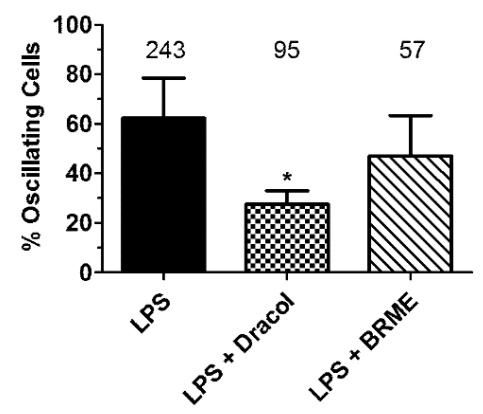

B

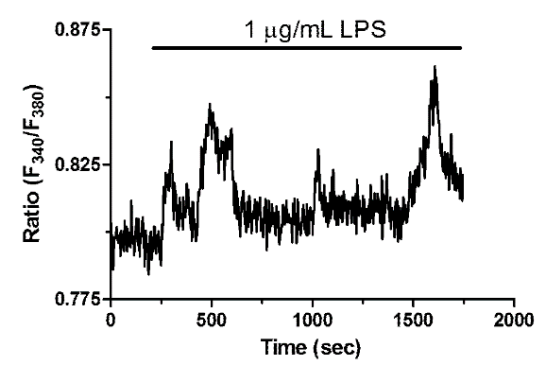

$\mathbf{F}$

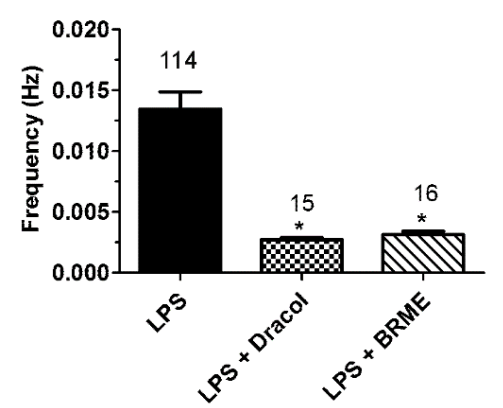

Figure 6. LPS-induced intracellular $\mathrm{Ca}^{2+}$ oscillations are impaired after treatment with BRME and Dracol. The acute application of LPS $(1 \mu \mathrm{g} / \mathrm{mL})$ induced either a single $\mathrm{Ca}^{2+}$ spike (A) or repetitive oscillations in $\left[\mathrm{Ca}^{2+}\right] \mathrm{i}(\mathbf{B})$. Intracellular $\mathrm{Ca}^{2+}$ oscillations recorded after treatment with $1 \mu \mathrm{g} / \mathrm{mL}$ LPS for $4 \mathrm{~h}$ were attenuated in the presence of Dracol and BRME (C). Mean \pm SE of the percentage of oscillating cells (D), of the amplitude of the 1st $\mathrm{Ca}^{2+}$ spike (E), and of the frequency of $\mathrm{Ca}^{2+}$ oscillations (F) under the designated treatments, from three independent experiments. ${ }^{*} p \leq 0.05$ by Student's $t$ test. 
In agreement with these observations, intracellular oscillations in $\left[\mathrm{Ca}^{2+}\right]_{\mathrm{i}}$ were detected in the majority of THP1 cells pre-treated with $1 \mu \mathrm{g} / \mathrm{mL}$ LPS for $4 \mathrm{~h}$ (Figure 6C,D), whereas the remaining cells displayed only one $\mathrm{Ca}^{2+}$ transient during the period of recording (not shown). These repetitive $\mathrm{Ca}^{2+}$ spikes were similar to those recorded in mouse pulmonary artery endothelial cells previously exposed to $1 \mu \mathrm{g} / \mathrm{mL}$ LPS for $16 \mathrm{~h}$ [26]. Of note, $1 \mu \mathrm{g} / \mathrm{mL}$ LPS failed to induce intracellular $\mathrm{Ca}^{2+}$ oscillations in THP1 cells pre-treated with BAPTA-AM (30 $\mu \mathrm{M}, 2 \mathrm{~h})$ (Supplementary Material S3), which confirms that intracellular $\mathrm{Ca}^{2+}$ signaling was required to induce the nuclear translocation of NF-kB [27]. However, Dracol $(10 \mu \mathrm{M})$ and BRME $(250 \mu \mathrm{g} / \mathrm{mL})$ reduced the percentage of oscillating cells (Figure 6C), although the statistical significance was achieved only upon pre-treatment with Dracol (Figure 6C). In addition, Dracol $(10 \mu \mathrm{M})$ and BRME $(250 \mu \mathrm{g} / \mathrm{mL})$ decreased the frequency and amplitude of the $1^{\text {st }} \mathrm{Ca}^{2+}$ spike of LPS-induced intracellular $\mathrm{Ca}^{2+}$ transients (Figure $6 \mathrm{E}, \mathrm{F}$ ). In the majority of non-excitable cells, intracellular $\mathrm{Ca}^{2+}$ oscillations are supported by rhythmical $\mathrm{InsP}_{3}$-dependent $\mathrm{Ca}^{2+}$ release from the endoplasmic reticulum (ER), the largest endogenous $\mathrm{Ca}^{2+}$ store, whereas SOCE is required to sustain the $\mathrm{Ca}^{2+}$ spikes over time by refilling the ER with the $\mathrm{Ca}^{2+}$ necessary to set up the next $\mathrm{Ca}^{2+}$ spike $[19,20,26]$.

As Dracol and BRME affect the frequency and magnitude of LPS-induced $\mathrm{Ca}^{2+}$ spikes, further work will examine whether and how these compounds impair the expression and/or function of the components of the $\mathrm{Ca}^{2+}$ toolkit involved in the spiking response to LPS.

\section{Materials and Methods}

\subsection{Reagents}

LPS and all other chemicals of reagents grade were obtained from Sigma (St. Louis, MO, USA) unless otherwise specified.

\subsection{Plant Materials}

Bellevalia saviczii was collected on April 2014 in the Zraraty district in Erbil-Kurdistan region. The materials were identified and classified at the Education Salahaddin University Herbarium (ESUH) by prof. Abdullah Shakur Sardar, of the University of Salahaddin, Erbil-Iraq. A voucher specimen (7702) was deposited. Roots were cleaned and air-dried in the shade at room temperature (r.t.) $\left(20-25^{\circ} \mathrm{C}\right)$. After drying, the plant material was grounded using a laboratory grinding mill and the resulting powder was stored in dark bottles at r.t. until required.

\subsection{Root Extraction and Compound Isolation}

B. saviczii roots $(100 \mathrm{~g})$ were soaked in petroleum ether $(500 \mathrm{~mL})$ in an ultra-sonic bath for $30 \mathrm{~min}$, and then left in the same solvent for $3 \mathrm{~h}$ under continuous stirring at r.t. The procedure was repeated three times. Defatted roots were subsequently soaked in methanol $(\mathrm{MeOH})(500 \mathrm{~mL})$ in an ultra-sonic bath for $30 \mathrm{~min}$, then left in the same solvent for $3 \mathrm{~h}$ under continuous stirring at $\mathrm{r}$. $\mathrm{t}$. The procedure was repeated three times. The mixtures were then filtered and the solvent removed under vacuum in a rotary evaporator to afford $(2.0 \mathrm{~g})$ of crude $\mathrm{MeOH}$ residues extract (BRME) from roots.

Subsequently, BRME fraction $(2.0 \mathrm{~g})$ was suspended in $500 \mathrm{~mL}$ of $40 \%$ aqueous $\mathrm{MeOH}$ and then extracted with dichloromethane $(500 \mathrm{~mL})$ to afford a dichloromethane soluble fraction $(459.6 \mathrm{mg})$ which was called BRD. $459.6 \mathrm{mg}$ of BRD were suspended in $10 \mathrm{~mL}$ of $\mathrm{H}_{2} \mathrm{O} / \mathrm{MeOH} 80 / 20$, and then charged on the $\mathrm{C}_{18}$ column. The first solvent system $\left(\mathrm{H}_{2} \mathrm{O} / \mathrm{MeOH} 80 / 20\right)$ was added to the column and the elution started with gradient system to $100 \% \mathrm{MeOH}$ at the flow rate of $10 \mathrm{~mL} / \mathrm{min} ; 500 \mathrm{~mL}$ were necessary to complete the elution of fractions. The column was finally washed with $165 \mathrm{~mL}$ of $100 \% \mathrm{MeOH}$. After evaporation of the solvent under vacuum, BRD1 (121.4 mg), BRD2 (217.3 mg), BRD3 (76.9 mg), BRD4 (9.17 mg) and BRD5 (12.8 mg) fractions were obtained. 
The fraction BRD4 $(9.17 \mathrm{mg})$, eluted $\left(\mathrm{H}_{2} \mathrm{O} / \mathrm{MeOH} 3 / 7\right)$ on a Merck Aluminum-backed RP-18 TLC plate and revealed as a yellow spot upon exposure to the vanillin-sulphuric acid reagent and gentle heating, resulted to be a pure compound, later identified as compound (1) named Dracol (Scheme 1).

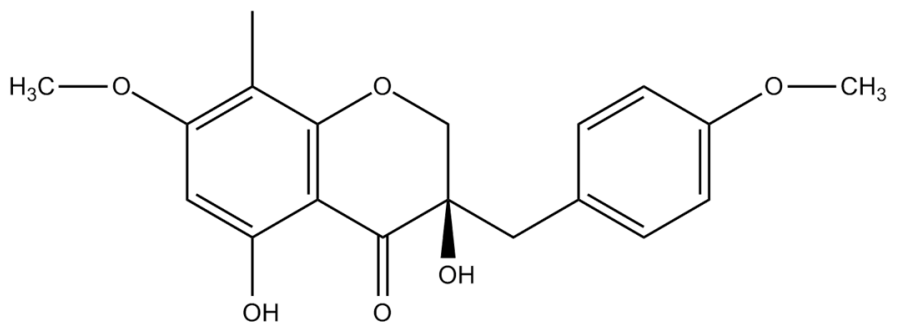

Scheme 1. Chemical structure of homoisoflavonoid (Dracol) isolated from B. saviczii roots.

\subsection{Spectral Data of Isolated Compound}

Compound (1): $\quad(\quad=$ (3R)-2,3-Dihydro-3,5-dihydroxy-7-methoxy-3-[(4-methoxyphenyl) methyl]-8-methyl-4H-[1]-benzopyran-4-one). Pale yellow amorphous solid, yield: (9.17 mg), Molecular formula $\mathrm{C}_{19} \mathrm{H}_{20} \mathrm{O}_{6}$ deduced from the negative-ion ESIMS- spectrum ([M - H] $\left.]^{-} \mathrm{m} / \mathrm{z} 345.28,239.25\right) ; \mathrm{UV}$ $(\mathrm{MeOH}) \lambda_{\max } 290.5,375.5 \mathrm{~nm} ;{ }^{1} \mathrm{H}-\mathrm{NMR}\left(\mathrm{CD}_{3} \mathrm{OD}, 300 \mathrm{MHz}\right) 3.99(\mathrm{H} \beta, \mathrm{d}, J=12.0, \mathrm{H}-2), 4.04(\mathrm{H} \alpha, \mathrm{d}$, $J=12.0, \mathrm{H}-2), 6.15$ (1H, s., H-6), 2.92 (2H, d, J = 5.5, H-9), 1.95 (3H, 2, H-8 Me), 3.76 (3H, s, OMe), 3.87 $(3 \mathrm{H}, \mathrm{s}, \mathrm{OMe}), 6.82\left(1 \mathrm{H}, \mathrm{d}, J=8.6, \mathrm{H}-2^{\prime}\right), 7.14\left(1 \mathrm{H}, \mathrm{d}, J=8.6, \mathrm{H}-3^{\prime}\right), 7.14\left(1 \mathrm{H}, \mathrm{d}, J=8.6, \mathrm{H}-5^{\prime}\right)$, and 6.82 $\left(1 \mathrm{H}, \mathrm{d}, J=8.6, \mathrm{H}-6^{\prime}\right) .{ }^{13} \mathrm{C}-\mathrm{NMR}\left(\mathrm{CD}_{3} \mathrm{OD}, 300 \mathrm{MHz}\right): \delta_{\mathrm{C}} 14.51(\mathrm{C}-8 \mathrm{Me}), 61.7(\mathrm{OMe}), 61.9(\mathrm{OMe}), 70.9$ (C-2), 62.9 (C-3), 201.5 (C-4), 146.9 (C-5), 105.16 (C-6), 149.7 (C-7), 130.3 (C-8), 33.1 (C-9), 135.5 (C-4a), $151.72(\mathrm{C}-8 \mathrm{a}), 121.8\left(\mathrm{C}-1^{\prime}\right), 131.9\left(\mathrm{C}-2^{\prime}\right), 116.7\left(\mathrm{C}-3^{\prime}\right), 157.6\left(\mathrm{C}-4^{\prime}\right), 116.7\left(\mathrm{C}-5^{\prime}\right)$ and $131.5\left(\mathrm{C}-6^{\prime}\right)$. The ${ }^{1} \mathrm{H}$ and ${ }^{13} \mathrm{C}-\mathrm{NMR}$ spectra were in agreement with the literature [3].

\subsection{In Vitro Cell Culture and Treatments}

Human leukemic monocytic cell line (THP1) provided by Istituto Zooprofilattico di Brescia (Italy) were cultured in RPM1 1640 medium with $10 \%$ of $\mathrm{FBS}$ at $37^{\circ} \mathrm{C}$ in a humidified $\mathrm{CO}_{2}(5 \%)$ incubator.

Fifty-four mg of BRME were dissolved in Dimethyl sulfoxide (DMSO) at the concentration of $720 \mu \mathrm{g} / \mu \mathrm{L}$. Dracol, isolated from BRME, was prepared as a stock solution in DMSO (150 mM) and diluted directly in cell culture medium. Final concentration of DMSO did not exceed $0.15 \%(v / v)$ and control cells were treated with the same concentration of vehicle that did not exert any effect in all the assays.

THP1 cells have been treated for $24 \mathrm{~h}$ with different concentrations of the total root extract or Dracol. To perform the immobilization of cell suspension cultures, at the end of each treatment, the cells were washed with PBS and resuspended in serum-free medium before transferring to a culture plate containing coverslips [28]. LPS was used to set up the cellular inflammatory model $[6,29]$ and preliminary experiments were performed to optimize timing and dosages of LPS treatment for activating THP1 cells. In particular, three increasing concentrations of LPS $(0.01-0.1-1 \mu \mathrm{g} / \mathrm{mL})$ and two different incubation times were used to identify the better condition for the subsequent experiments. The negative controls consisted of untreated cells while the positive ones were LPS-treated. From these preliminary approaches, THP1 cells treated for $24 \mathrm{~h}$ with different concentrations of BRME or Dracol and then stimulated with LPS $(1 \mu \mathrm{g} / \mathrm{mL}$ for $4 \mathrm{~h})$ provided an efficient and reproducible model to study monocyte inflammatory response. In addition, THP1 cells were treated for $2 \mathrm{~h}$ with the calcium chelator BAPTA-AM $(30 \mu \mathrm{M})$ alone and/or in combination with LPS $(1 \mu \mathrm{g} / \mathrm{mL})$ in the above conditions.

\subsection{Cytotoxicity, Proliferation and Trypan Blue Exclusion Assay}

The cytotoxicity of BRME and Dracol, both by themselves and in combination with LPS, was evaluated by MTT assay and Trypan Blue staining, as previously described [30]. Cell cycle 
experiments were performed by using 5-bromo-2'-deoxyuridine incorporation (BrdU), as previously reported [31].

\subsection{NF-kB Staining}

As a marker of NF-kB activation, the nuclear translocation of the $\mathrm{p} 65 \mathrm{NF}-\mathrm{kB}$ subunit was visualized in THP1 cells by immunofluorescence microscopy and Western blotting. After $4 \mathrm{~h}$ treatment with LPS in serum free medium, cells seeded on coverslips and pre-incubated for $24 \mathrm{~h}$ with compounds, were fixed in $4 \%$ PFA and $70 \%$ ethanol and then stored overnight at $-20{ }^{\circ} \mathrm{C}$. After washing with PBS, the samples were blocked in PBS containing 5\% FBS, and then incubated overnight at $4{ }^{\circ} \mathrm{C}$ in a humidified chamber with the specific monoclonal anti-NF-kB p65 antibody (F-6) (sc-8008 Santa Cruz) diluted 1:200 in PBS. After washing, each reaction was followed by incubation for $1 \mathrm{~h}$ with anti-mouse conjugated with Alexa Fluor 488 (1:200; Invitrogen Molecular Probes, USA). The cells were incubated with Hoechst 33258 (1:5000) for $5 \mathrm{~min}$ at r.t. and then washed with PBS. Slides were mounted in Mowiol (Calbiochem) containing 0.25\% 1,4-diazabicyclo-[2,2,2]-octane (Aldrich) as antifading agent. Images of the fixed THP1 cells were taken with Olympus IX 83(60/1.24) or OlympusBX-51 microscopes (100X immersion oil lens, NA 1.25) equipped with an Olympus C4040 camera. The concentration of NF-kB was also determined by Western blotting using the p65 antibody (F-6) (sc-8008 Santa Cruz) diluted 1:1000 in PBS/Tween20 (0.2\%), as previously described [30].

\subsection{Cytokine Analysis}

At the end of the cell treatment, as above described, the supernatant of the centrifuged media was collected and stored at $-80^{\circ} \mathrm{C}$. Concentrations of TNF $\alpha$ and IL 6 were determined by enzyme-linked immunosorbent assay (ELISA) according to the manufacturer's protocol (Thermo Scientific, USA), using the antibodies C-4, sc-133192 and E4, sc-28343 (Santa Cruz, Biotechnology Inc. Heidelberg, Germany), respectively. The concentration of IL1 $\beta$ was determined by western blotting using the antibody E7-2-hIL1ß (sc-32294, Santa Cruz, Biotechnology Inc. Heidelberg, Germany), as previously described [30]. Densitometric analysis for IL1 $\beta$ was performed on both bands obtained, considering that 31 and $17 \mathrm{KDa}$ are the precursor and mature forms of the protein, respectively.

\section{9. $\left[\mathrm{Ca}^{2+}\right]_{i}$ Measurements}

LPS-induced intracellular $\mathrm{Ca}^{2+}$ oscillations were measured as described elsewhere [18]. At the end of the treatment for $4 \mathrm{~h}$ with LPS $(1 \mu \mathrm{g} / \mathrm{mL})$, THP1 cells were loaded with $4 \mu \mathrm{M}$ fura- 2 acetoxymethyl ester (Fura-2/AM; $1 \mathrm{mM}$ stock in DMSO in physiological salt solution (PSS) for $20 \mathrm{~min}$ at $37^{\circ} \mathrm{C}, 5 \%$ $\mathrm{CO}_{2}$ saturated humidity. When the cells were pre-treated for $24 \mathrm{~h}$ with $10 \mu \mathrm{M}$ Dracol and $250 \mu \mathrm{g} / \mathrm{mL}$ BRME, LPS $(1 \mu \mathrm{g} / \mathrm{mL})$ was added for $4 \mathrm{~h}$ at the end of the incubation period and the $\mathrm{Ca}^{2+}$ signals then evaluated. PSS had the following composition (in $\mathrm{mM}$ ): $150 \mathrm{NaCl}, 6 \mathrm{KCl}, 1.5 \mathrm{CaCl}_{2}, 1 \mathrm{MgCl}_{2}$, 10 Glucose, 10 Hepes and was titrated to $\mathrm{pH} 7.4$ with $\mathrm{NaOH}$. The osmolality of PSS as measured with an osmometer (Wescor 5500, Logan, UT) was $338 \mathrm{mmol} / \mathrm{kg}$.

After washing in PSS, the coverslips were fixed to the bottom of a Petri dish and the cells observed by an upright epifluorescence Axiolab microscope (Carl Zeiss, Oberkochen, Germany), usually equipped with a Zeiss $\times 40$ Achroplan objective (water-immersion, $2.0 \mathrm{~mm}$ working distance, 0.9 numerical aperture). The cells were excited alternately at 340 and $380 \mathrm{~nm}$, and the emitted light was detected at $510 \mathrm{~nm}$. A first neutral density filter (1 or 0.3 optical density) reduced the overall intensity of the excitation light and a second neutral density filter (optical density $=0.3$ ) was coupled to the $380 \mathrm{~nm}$ filter to approach the intensity of the $340 \mathrm{~nm}$ light. A round diaphragm was used to increase the contrast. The excitation filters were mounted on a filter wheel (Lambda 10, Sutter Instrument, Novato, CA, USA). Custom software, working in the LINUX environment, was used to drive the camera (Extended-ISIS Camera, Photonic Science, Millham, UK) and the filter wheel, and to measure and plot on-line the fluorescence from 30-45 rectangular "regions of interest" (ROI) enclosing 20-30 single cells. Each ROI was identified by a number. Adjacent ROIs never superimposed. $\left[\mathrm{Ca}^{2+}\right]_{\mathrm{i}}$ 
was monitored by measuring, for each ROI, the ratio of the mean fluorescence emitted at 510 nm when exciting alternatively at 340 and $380 \mathrm{~nm}$ [Ratio $\left.\left(\mathrm{F}_{340} / \mathrm{F}_{380}\right)\right]$. An increase in $\left[\mathrm{Ca}^{2+}\right]_{\mathrm{i}}$ causes an increase in the ratio [18]. Ratio measurements were performed and plotted on-line every 3 sec. The experiments were performed at r.t. $\left(22^{\circ} \mathrm{C}\right)$.

\subsection{Statistical Analysis}

Data are presented as means \pm SD. Statistical analysis was performed by using the Student's $t$-test where only probability values ${ }^{*} p \leq 0.05,{ }^{* *} p \leq 0.01$ were considered to be statistically significant. Intracellular $\mathrm{Ca}^{2+}$ oscillations were analyzed by measuring the percentage of oscillating cells for each condition (LPS, LPS + BRME, LPS + Dracol), the amplitude of the $1^{\text {st }}$ spike and the frequency of $\mathrm{Ca}^{2+}$ over $1000 \mathrm{~s}$. Pooled data are presented as means \pm SE and the number of analyzed cells is reported above or within column bars. Each data is representative of four different coverslips. Statistical significance $(p \leq 0.05)$ was evaluated by the Student's $t$-test for unpaired observations.

\section{Conclusions}

The present study demonstrated that the root of B. saviczii, which has been traditionally used in Iraqi-Kurdistan as a medicinal plant, is a valuable source of active compounds, especially homoisoflavonoids. Among them, Dracol has been identified for the first time in this plant and, in our experimental conditions, it is able to prevent the NF-kB activation induced in human monocytes by LPS treatment. Very few studies have considered the biological activity of this compounds, which deserves further investigation, particularly regarding their use in treating inflammatory diseases. The observed decrease in nuclear translocation of p65 NF-kB subunit, associated with TNF $\alpha$ release reduction, strongly depend on the modification of calcium signaling.

Supplementary Materials: The following are available online at http://www.mdpi.com/1420-3049/24/18/3376/s1. Supplementary material S1 describes more in detail the extraction and purification of B. saviczii preparation. Supplementary material S2 includes all the data obtained treating cells with the only compounds. Supplementary material S3 shows $\mathrm{Ca}^{2+}$ level in THP1 treated with BAPTA-AM and LPS.

Author Contributions: A.S.S. collected, identified and classified B. saviczii. M.F.I. has carried out the chemical extraction and isolation of compounds under the supervision of G.B.; M.S. with the help of C.S. and G.A. have performed the cellular experiments under the supervision of L.A.S. The calcium signaling experiments were designed and executed by F.M. helped by M.O. Data analysis and manuscript writing were performed by M.S., M.F.I., F.M., L.A.S. and G.B. All the authors have read and approved the manuscript submitted for the first time.

Funding: This research was funded by the Italian Ministry of Education, University and Research (MIUR) to the Departments of Molecular Medicine (DMM) and Biology and Biotechnologies (DBB) of the University of Pavia under the initiative "Dipartimenti di Eccellenza (2018-2022)".

Acknowledgments: The Authors acknowledge the Center for International Cooperation and Development CICOPS for the support for the isolation and characterization activities.

Conflicts of Interest: The authors declare no conflict of interest.

\section{References}

1. Lin, L.G.; Liu, Q.Y.; Ye, Y. Naturally occurring homoisoflavonoids and their pharmacological activities. Planta Med. 2014, 80, 1053-1066. [CrossRef] [PubMed]

2. Alali, F.; El-Elimat, T.; Albataineh, H.; Al-Balas, Q.; Al-Gharaibeh, M.; Falkinham, J.O.; Chen, W.L.; Swanson, S.M.; Oberlies, N.H. Cytotoxic Homoisoflavones from the Bulbs of Bellevalia eigii. J. Nat. Prod. 2015, 78, 1708-1715. [CrossRef] [PubMed]

3. Hernández, J.C.; León, F.; Estévez, F.; Quintana, J.; Bermejo, J. A homo-isoflavonoid and a cytotoxic saponin from Dracaena draco. Chem. Biodivers 2006, 3, 62-68. [CrossRef]

4. Hafez Ghoran, S.; Saeidnia, S.; Babaei, E.; Kiuchi, F.; Hussain, H. Scillapersicene: A new homoisoflavonoid with cytotoxic activity from the bulbs of Scilla persica HAUSSKN. Nat. Prod. Res. 2016, 30, 1309-1314. [CrossRef] [PubMed] 
5. Zhou, X.; Yuping, Z.; Zhao, H.; Liang, J.; Zhang, Y.; Shi, S. Antioxidant homoisoflavonoids from Polygonatum odoratum. Food Chem. 2015, 186, 63-68. [CrossRef] [PubMed]

6. Wang, Y.; Liu, F.; Liang, Z.; Peng, L.; Wang, B.; Yu, J.; Su, Y.; Ma, C. Homoisoflavonoids and the Antioxidant Activity of Ophiopogon japonicus Root. Iran J. Pharm. Res. 2017, 16, 357-365.

7. Roy, S.K.; Agrahari, U.C.; Gautam, R.; Srivastava, A.; Jachak, S.M. Isointricatinol, a new antioxidant homoisoflavonoid from the roots of Caesalpinia digyna Rottler. Nat. Prod. Res. 2012, 26, 690-695. [CrossRef]

8. Hung, T.M.; Thu, C.V.; Dat, N.T.; Ryoo, S.W.; Lee, J.H.; Kim, J.C.; Na, M.; Jung, H.J.; Bae, K.; Min, B.S. Homoisoflavonoid derivatives from the roots of Ophiopogon japonicus and their in vitro anti-inflammation activity. Bioorg. Med. Chem. Lett. 2010, 20, 2412-2416. [CrossRef]

9. Famuyiwa, S.O.; Ntumy, A.N.; Andrae-Marobela, K.; Yeboah, S.O. A new homoisoflavonoid and the bioactivities of some selected homoisoflavonoids from the inter-bulb surfaces of Scilla nervosa subsp. rigidifolia. South Afr. J. Bot. 2013, 88, 17-22. [CrossRef]

10. Adinolfi, M. Homoisoflavanones from Bellevalia romana. Phytochemistry 1989, 28, 3244-3246. [CrossRef]

11. Lawrence, T. The nuclear factor NF-kappaB pathway in inflammation. Cold Spring Harb. Perspect Biol. 2009, 1, a001651. [CrossRef] [PubMed]

12. Hoesel, B.; Schmid, J.A. The complexity of NF-kB signaling in inflammation and cancer. Mol. Cancer 2013, 12, 86. [CrossRef] [PubMed]

13. Hund, A.C.; Lockmann, A.; Schön, M.P. Mutually enhancing anti-inflammatory activities of dimethyl fumarate and NF-kB inhibitors-implications for dose-sparing combination therapies. Exp. Derm. 2016, 25, 124-130. [CrossRef] [PubMed]

14. Zhu, M.; Du, J.; Liu, A.D.; Holmberg, L.; Chen, S.Y.; Bu, D.; Tang, C.; Jin, H. L-cystathionine inhibits oxidized low density lipoprotein-induced THP-1-derived macrophage inflammatory cytokine monocyte chemoattractant protein-1 generation via the NF-kB pathway. Sci. Rep. 2015, 5, 10453. [CrossRef] [PubMed]

15. Frantz, B.; Nordby, E.C.; Bren, G.; Steffan, N.; Paya, C.V.; Kincaid, R.L.; Tocci, M.J.; O’Keefe, S.J.; O’Neill, E.A. Calcineurin acts in synergy with PMA to inactivate I kappa B/MAD3, an inhibitor of NF-kappa B. EMBO J. 1994, 13, 861-870. [CrossRef]

16. Hughes, K.; Antonsson, A.; Grundstrøm, T. Calmodulin dependence of NFkappaB activation. FEBS Lett. 1998, 441, 132-136. [CrossRef]

17. Dolmetsch, R.E.; Xu, K.; Lewis, R.S. Calcium oscillations increase the efficiency and specificity of gene expression. Nature 1998, 392, 933-936. [CrossRef]

18. Dragoni, S.; Laforenza, U.; Bonetti, E.; Lodola, F.; Bottino, C.; Berra-Romani, R.; Carlo Bongio, G.; Cinelli, M.P.; Guerra, G.; Pedrazzoli, P.; et al. Vascular endothelial growth factor stimulates endothelial colony forming cells proliferation and tubulogenesis by inducing oscillations in intracellular $\mathrm{Ca}^{2+}$ concentration. Stem. Cells 2011, 29, 1898-1907. [CrossRef] [PubMed]

19. Kandasamy, K.; Bezavada, L.; Escue, R.B.; Parthasarathi, K. Lipopolysaccharide induces endoplasmic store $\mathrm{Ca}^{2+}$-dependent inflammatory responses in lung microvessels. PLoS ONE 2013, 8, e63465. [CrossRef]

20. Liu, F.; Zhou, R.; Yan, H.; Yin, H.; Wu, X.; Tan, Y.; Li, L. Metabotropic glutamate receptor 5 modulates calcium oscillation and innate immune response induced by lipopolysaccharide in microglial cell. Neuroscience 2014, 281, 24-34. [CrossRef]

21. Smedler, E.; Uhlén, P. Frequency decoding of calcium oscillations. Biochim. Biophys. Acta 2014, 1840, 964-969. [CrossRef] [PubMed]

22. Valente, M.J.; Guedes de Pinho, P.; Henrique, R.; Pereira, J.A.; Carvalho, M. Further insights into chemical characterization through GC-MS and evaluation for anticancer potential of Dracaena draco leaf and fruit extracts. Food Chem. Toxicol. 2012, 50, 3847-3852. [CrossRef] [PubMed]

23. Willerson, J.T.; Ridker, P.M. Inflammation as a cardiovascular risk factor. Circulation 2004, 109, II-2-II-10. [CrossRef] [PubMed]

24. Donath, M.Y.; Shoelson, S.E. Type 2 diabetes as an inflammatory disease. Nat. Rev. Immunol. 2011, 11, 98-107. [CrossRef] [PubMed]

25. Amor, S.; Puentes, F.; Baker, D.; van der Valk, P. Inflammation in neurodegenerative diseases. Immunology 2010, 129, 154-169. [CrossRef] [PubMed] 
26. Gandhirajan, R.K.; Meng, S.; Chandramoorthy, H.C.; Mallilankaraman, K.; Mancarella, S.; Gao, H.; Razmpour, R.; Yang, X.F.; Houser, S.R.; Chen, J.; et al. Blockade of NOX2 and STIM1 signaling limits lipopolysaccharide-induced vascular inflammation. J. Clin. Investig. 2013, 123, 887-902. [CrossRef] [PubMed]

27. Jembrek, M.J.; Vlainić, J.; Radovanović, V.; Erhardt, J.; Oršolic, N. Effects of copper overload in P19 neurons: Impairment of glutathione redox homeostasis and crosstalk between caspase and calpain protease systems in ROS-induced apoptosis. Biometals 2014, 27, 1303-1322. [CrossRef]

28. Nakayama, T.; Mihara, K.; Kawata, J.; Kimura, H.; Saitoh, H. Adhesion of suspension cells on a coverslip in serum-free conditions. Anal. Biochem. 2014, 466, 1-3. [CrossRef]

29. Ding, Y.; Liu, P.; Chen, Z.L.; Zhang, S.J.; Wang, Y.Q.; Cai, X.; Luo, L.; Zhou, X.; Zhao, L. Emodin Attenuates Lipopolysaccharide-Induced Acute Liver Injury via Inhibiting the TLR4 Signaling Pathway. Front. Pharm. 2018, 9, 962. [CrossRef]

30. Maccario, C.; Savio, M.; Ferraro, D.; Bianchi, L.; Pizzala, R.; Pretali, L.; Forti, L.; Stivala, L.A. The resveratrol analog 4,4'-dihydroxy-trans-stilbene suppresses transformation in normal mouse fibroblasts and inhibits proliferation and invasion of human breast cancer cells. Carcinogenesis 2012, 33, 2172-2180. [CrossRef]

31. Savio, M.; Coppa, T.; Bianchi, L.; Vannini, V.; Maga, G.; Forti, L.; Cazzalini, O.; Lazzè, M.C.; Perucca, P.; Prosperi, E.; et al. The resveratrol analogue 4,4'-dihydroxy-trans-stilbene inhibits cell proliferation with higher efficiency but different mechanism from resveratrol. Int. J. Biochem. Cell Biol. 2009, 41, 2493-2502. [CrossRef] [PubMed]

Sample Availability: Samples of the compounds are not available from the authors.

(C) 2019 by the authors. Licensee MDPI, Basel, Switzerland. This article is an open access article distributed under the terms and conditions of the Creative Commons Attribution (CC BY) license (http://creativecommons.org/licenses/by/4.0/). 